\title{
Hemophagocytic lymphohistiocytosis and pulmonary alveolar proteinosis in a 13-month-old boy with lysinuric protein intolerance
}

\author{
Robert F. Stanley ${ }^{1}$, Michael Licata ${ }^{1}$, Arpan Sinha ${ }^{2}$, Yanhua Wang*1 \\ ${ }^{1}$ Department of Pathology, Albert Einstein College of Medicine, Montefiore Medical Center, Bronx, NY 10467, USA \\ ${ }^{2}$ Department of Pediatrics, Albert Einstein College of Medicine, Montefiore Medical Center, Bronx, NY 10467, USA
}

Received: June 14, 2017

DOI: $10.5430 /$ crcp.v4n3p19
Accepted: August 8, 2017

Online Published: September 29, 2017

URL: https://doi.org/10.5430/crcp.v4n3p19

\begin{abstract}
Hemophagocytic lymphohistiocytosis (HLH) is a clinical syndrome that can be inherited or acquired. Herein, we report a case of HLH and pulmonary alveolar proteinosis (PAP) in the setting of lysinuric protein intolerance (LPI) in a male toddler who presented with prolonged fever, respiratory distress, and failure to thrive. On histologic examination, hemophagocytosis was observed in lymph node, bone marrow sections and aspirates. Lung wedge resection was consistent with PAP. LPI was confirmed with genetic sequencing which revealed compound heterozygous mutations in the SLC7A7 gene. LPI is a rare inborn error of metabolism and is not widely known beyond the pediatric group. Though the association of LPI with HLH has been previously described, we believe this is the first reported case of HLH and PAP associated LPI with histopathological correlation. Early recognition of HLH is critical to successful treatment and LPI should be considered in any young infant who presents with HLHand PAP-related symptoms.
\end{abstract}

Key Words: Hemophagocytic lymphohistiocytosis, Lysinuric protein intolerance, Pulmonary alveolar proteinosis, SLC7A7

\section{INTRODUCTION}

Hemophagocytic lymphohistiocytosis (HLH) is a rare lifethreatening clinical hyperinflammatory syndrome that leads to excessive activation of immune cells resulting in hypercytokinemia that can lead to multi-organ failure and death. ${ }^{[1]}$ HLH was first described by Farquhar and Claireaux in $1952^{[2]}$ and is characterized by prolonged fever, cytopenias, hepatosplenomegaly, abnormal lab values and the presence of hemophagocytosis (for complete diagnostic criteria see $\mathrm{e}^{[3]}$ ). HLH can be dichotomized into primary (genetic) or secondary (acquired) causes and is associated with many underlying conditions affecting all age groups regardless of the principal etiology. ${ }^{[1,4]}$ Primary HLH occurs due to genetic aberrations that affect the perforin-mediated cytotoxic abilities of T cells and natural killer cells, whereas, acquired HLH typically occurs in adults secondary to infection, malignancy, rheumatologic disease or immune suppression. ${ }^{[5]}$ Several hereditary immunodeficiency syndromes predispose patients to HLH and HLH is frequently the first manifestation of such diseases. ${ }^{[6]}$

Lysinuric protein intolerance (LPI) is a rare autosomal recessive disease that is caused by mutations in the SLC7A7 gene leading to dysfunction of the cationic amino acid trans-

\footnotetext{
* Correspondence: Yanhua Wang, M.D., Ph.D.; Email: YWANG@montefiore.org; Address: Department of Pathology, Albert Einstein College of Medicine, Montefiore Medical Center, 111E 210th Street, Bronx, NY 10467, USA.
} 
porter (lysine, ornithine, arginine) subunit y+LAT1, which mainly affects intestinal and renal cells. ${ }^{[7,8]}$ Patients with LPI have a highly variable clinical presentation ranging from mild protein intolerance, hepatosplenomegaly and hematologic abnormalities to severe manifestations such as failure to thrive, pulmonary alveolar proteinosis (PAP), kidney failure and immune deficiency. ${ }^{[9]}$ Patients with LPI have an increased susceptibility to HLH and HLH has previously been described in patients with LPI. ${ }^{[10,11]}$

In this article, we report the histopathological findings of a case of HLH and PAP in a patient with LPI. The patient presented with prolonged fever, failure to thrive and respiratory distress. Lymph node and bone marrow histopathology showed hemophagocytosis and lung tissue resection revealed accumulation of proteinaceous fluid. Genetic sequencing identified mutations in the SLC7A7 gene confirming a diagnosis of LPI.

\section{CASE PResentation}

A 13-month-old African American boy was admitted for prolonged fever, respiratory distress, diarrhea and failure to thrive. Childbirth was uncomplicated and the patient had been achieving developmental milestones until 6 months prior to presentation. The patient had 2 episodes of pneumonia within the past 6 months and 2 episodes of otitis media within the past year. Physical examination was significant for hepatosplenomegaly and lymphadenopathy. Clinically, this patient's presentation was suspicious for a lymphoproliferative disorder. Bone marrow biopsy and aspirate were performed, followed by an inguinal lymph node excisional biopsy. Laboratory data subsequently revealed anemia ( $\mathrm{Hb} 10.6 \mathrm{~g} / \mathrm{dl})$, increased ferritin $(>2,000 \mathrm{ng} / \mathrm{ml}, \max 8,500$ $\mathrm{ng} / \mathrm{ml})$, increased LDH (3,995 U/L), hypertriglyceridemia $(323 \mathrm{mg} / \mathrm{dl})$ and increased $\mathrm{IgE}(224 \mathrm{IU} / \mathrm{ml})$ with decreased fibrinogen.

\subsection{Methods}

Core bone marrow biopsy, bone marrow aspirate, lymph node biopsy and lung wedge resection were performed. Slides were stained with either hematoxylin and eosin (H\&E) or Wright-Giemsa stain and histological examination was performed. Next Generation Sequencing of a panel of HLH genes was performed by Cincinnati Children's HLH center of Excellence.

\subsection{Results}

Histological examination of an inguinal lymph node biopsy showed normal lymph node architecture with necrotic germinal centers (see Figure 1A, B). Tingible-body macrophages were present and histiocytes were filled with nucleated cells in the cytoplasm in the absence of neutrophils, eosinophils, and plasma cells, consistent with necrotizing lymphadenitis with hemophagocytosis (see Figure 1C).

Bone marrow core biopsy showed small clusters of macrophages digesting blood cells, similar to the findings within the lymph node (see Figure 1D). Bone marrow aspirate specimen confirmed these findings showing extensive hemophagocytosis in which macrophages or monocytes are digesting both red and white blood cells (see Figure 1E, F). The patient's clinical symptoms and histopathological findings were consistent with a diagnosis of HLH.

Despite treatment for HLH-related symptoms the patient's respiratory distress persisted and a lung wedge resection was performed. Pulmonary histopathology showed alveolar spaces filled with thick pink fluid and rod-like empty spaces (see Figure 2A-C). At higher magnification accumulation of proteinaceous fluid with surfactant lipids and proteins can be appreciated. These findings were consistent with a diagnosis of PAP, which is a syndrome characterized by defective macrophages and the accumulation of surfactant leading to impaired oxygenation, and respiratory distress. ${ }^{[12]}$

The patient's clinical presentation, in addition to the histopathological findings, were consistent with a primary cause of HLH and genetic testing was ordered. Next Generation Sequencing of an HLH panel of genes identified compound heterozygote frameshift and splice site mutations in the SLC7A7 gene, which occur in patients with LPI. Treatment was unsuccessful and the patient passed away secondary to respiratory failure.

\section{Discussion}

Herein, we report a case of a toddler presenting with HLH and PAP secondary to LPI. While HLH has been shown to be associated with LPI, few cases describe the histopathological findings in multiple tissues. ${ }^{[10,11]}$ Furthermore, while PAP is quite common in LPI, a recent retrospective cohort analysis found only 3 out of 16 cases of LPI had a diagnosis of HLH and PAP, illustrating how rare it is to have both disease entities present in the same patient. ${ }^{[13-15]}$

Differential considerations in young patients presenting with HLH-related symptoms include infection, immunodeficiency syndrome, lysosomal storage diseases and malignancy. Primary versus secondary etiologies of HLH can be difficult to distinguish in patients. Physicians should have high clinical suspicion for genetic causes of HLH in young patients presenting with HLH symptoms, however, it is not unreasonable to acquire genetic testing in any patient presenting with HLH symptoms as reports have shown that up to $14 \%$ of adults with HLH are suspected to have a genetic etiology. ${ }^{[4]}$ Clini- 
cal presentation, laboratory tests and histologic evaluation of formed to diagnose HLH. This patient exhibited 5/8 clinical bone marrow specimens and infiltrated organs should be per- diagnostic criteria for a diagnosis of HLH.

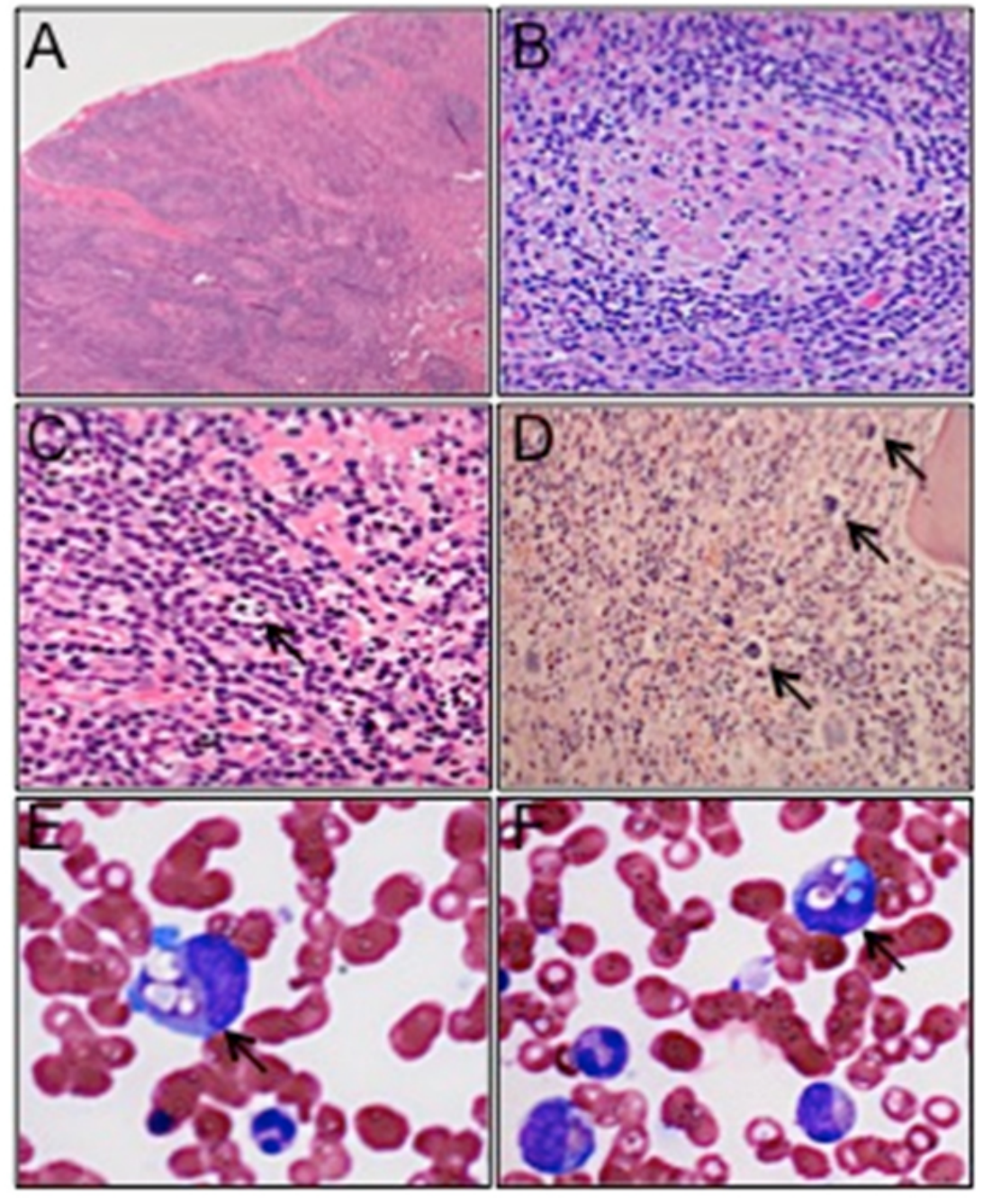

Figure 1. Histologic sections of inguinal lymph node, bone marrow core biopsy and bone marrow aspirate showing hemophagocytosis (A) Inguinal lymph node specimen showing intact lymph node architecture without extracapsular extension or hematoxylin bodies $(H \& E, \times 20)$. (B) Inguinal lymph node specimen at higher magnification showing a necrotic germinal center. ( $H \& E$, $\times 200$ ). (C) Tingible-body macrophages and histiocytes filled with nucleated cells are present within the inguinal lymph node specimen. (black arrow, $H \& E, \times 400$ ). (D) Bone marrow core biopsy specimen showing clusters of cells with nucleated forms within cells (black arrows, $H \& E$, $\times 100)$. $(E, F)$ Bone marrow aspirate highlighting the presence of hemophagocytosis (black arrows, Wright-Giemsa, $\times 1000$ ).
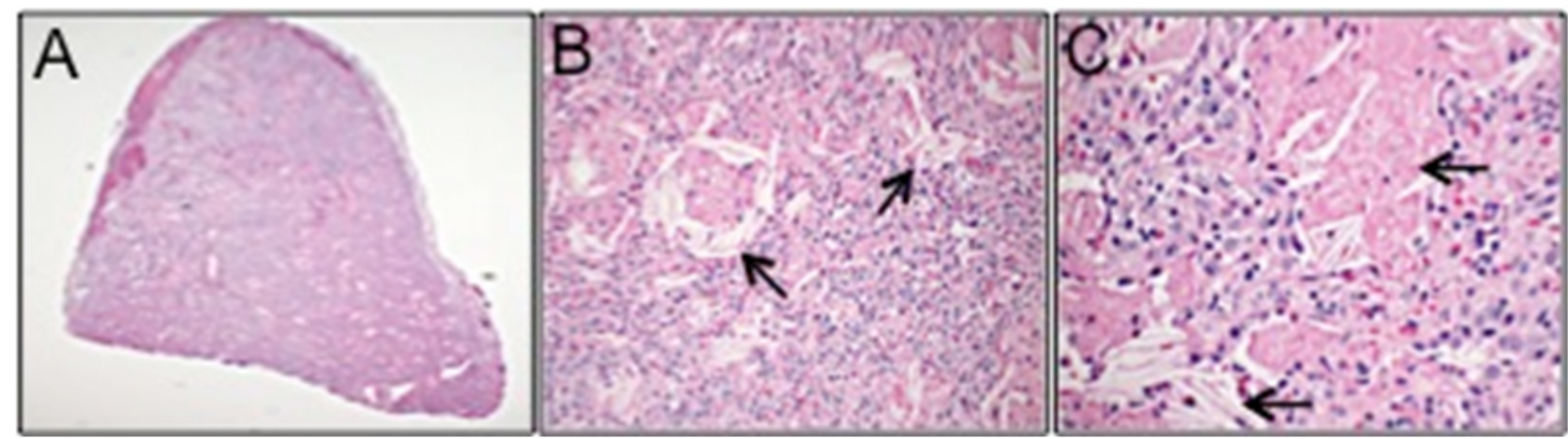

Figure 2. Lung wedge resection specimen demonstrating pulmonary alveolar proteinosis (A) Alveolar airspaces filled with thick, pink fluid and dense bodies $(H \& E, \times 20)$. (B,C) Higher magnification images showing accumulation of surfactant lipids and proteins within the pulmonary alveoli space and rod like spaces (black arrows, $H \& E, \times 100, \times 400$ ). 
The differential based on histopathological findings present on lymph node biopsy includes systemic lupus erythematosus (SLE) lymphadenitis, Kikuchi lymphadenitis, cat scratch lymphadenitis and HLH. SLE and Kikuchi can present with necrotizing lymphadenopathy and fibrinoid necrosis with nuclear debris. ${ }^{[16]}$ The distinguishing features of SLE lymphadenitis include hematoxylin bodies (most specific finding) and vascular fibrinoid necrosis as well as the presence of neutrophils and plasma cells. ${ }^{[17,18]}$ On the other hand Kikuchi typically presents with patchy necrosis and lacks neutrophils, eosinophils and plasma cells in affected foci. ${ }^{[19]}$ Cat scratch lymphadenitis presents with central necrosis with areas of apoptosis in the presence of neutrophils, lymphocytes and histiocytes. Tingible-body macrophages can be appreciated and there is characteristic deposition of pink amorphous intercellular proteinaceous materials. ${ }^{[20]}$ Importantly bacilli stain positive with Warthin-Starry stain in cat scratch disease whereas patients with Kikuchi have a negative WarthinStarrry stain. ${ }^{[20]}$ While hemophagocytosis can be present in all of these diseases, the presence of hemophagocytosis in the bone marrow is most consistent with HLH. Furthermore, SLE serologic testing and clinical history can help in narrowing the diagnosis.

The average survival for patients with familial HLH without treatment is approximately 1-2 months. ${ }^{[21]}$ Hematopoietic stem cell transplantation (HSCT) results in a 3-year overall survival of $50 \%$ or higher with the potential to cure disease, however HSCT has its own treatment related morbidity and mortality. ${ }^{[22-24]}$ Early recognition of HLH is critical to successful treatment. In conclusion, this case report highlights the histopathological findings of HLH and PAP, strengthens the association between HLH and LPI, and emphasizes the importance of a differential that includes LPI in any young patient who presents with HLH-related symptoms.

\section{CONFlicts of InTEREST Disclosure}

The authors declare that they have no competing interests.

\section{REFERENCES}

[1] Rosado FG, Kim AS. Hemophagocytic lymphohistiocytosis: an update on diagnosis and pathogenesis. Am J Clin Pathol. 2013 Jun; 139(6): 713-27. https://doi.org/10.1309/AJCP4ZDKJ4ICOU AT

[2] James WF, Albert EC. Familial haemophagocytic reticulosis. Archives of Disease in Childhood. 1952 Dec; 27(136): 519-525. https://doi.org/10.1136/adc.27.136.519

[3] Henter JI, Horne A, Aricó M, et al. HLH-2004: Diagnostic and therapeutic guidelines for hemophagocytic lymphohistiocytosis. Pediatric Blood \& Cancer. 2007 Feb; 48(2): 124-31. https : //doi .org/10 $.1002 / \mathrm{pbc} .21039$

[4] Zhang K, Jordan MB, Marsh RA, et al. Hypomorphic mutations in PRF1, MUNC13-4, and STXBP2 are associated with adult-onset familial hemophagocytic lymphohistiocytosis. Blood. 2011 Nov 24; 118(22): 5794-8. PMid: 21881043. https://doi.org/10.1182/ blood-2011-07-370148

[5] Morimoto A, Nakazawa Y, Ishii E. Hemophagocytic lymphohistiocytosis: Pathogenesis, diagnosis, and management. Pediatrics International. 2016 Sep; 58(9): 817-25. https://doi.org/10.1111/pe d. 13064

[6] Zhang L, Zhou J, Sokol L. Hereditary and acquired hemophagocytic lymphohistiocytosis. Cancer Control. 2014 Oct; 21(4): 301-12. https://doi.org/10.1177/107327481402100406

[7] Borsani G, Bassi MT, Sperandeo MP, et al. SLC7A7, encoding a putative permease-related protein, is mutated in patients with lysinuric protein intolerance. Nature Genetics. 1999 Mar; 21(3): 297-301. PMid: 10080183. https://doi.org/10.1038/6815

[8] Torrents D, Mykkänen J, Pineda M, et al. Identification of SLC7A7, encoding $\mathrm{y}+\mathrm{LAT}-1$, as the lysinuric protein intolerance gene. Nature Genetics. 1999 Mar; 21(3): 293-6. PMid: 10080182. https : //doi.org/10.1038/6809

[9] Ogier de Baulny H, Schiff M, Dionisi-Vici C. Lysinuric protein intolerance (LPI): a multi organ disease by far more complex than a classic urea cycle disorder. Molecular Genetics and Metabolism. 2012 May; 106(1): 12-7. PMid: 22402328. https ://doi.org/10 $.1016 / j$.ymgme .2012 .02 .010

[10] Duval M, Fenneteau O, Doireau V, et al. Intermittent hemophagocytic lymphohistiocytosis is a regular feature of lysinuric protein intolerance. The Journal of Pediatrics. 1999 Feb; 134(2): 236-9. https ://doi.org/10.1016/S0022-3476(99)70423-3

[11] Gordon WC, Gibson B, Leach MT, et al. Haemophagocytosis by myeloid precursors in lysinuric protein intolerance. British Journal of Haematology. 2007 Jul; 138(1): 1. https://doi .org/10.111 $1 / j .1365-2141.2007 .06594 . x$

[12] Seymour JF, Presneill JJ. Pulmonary alveolar proteinosis: progress in the first 44 years. American journal of respiratory and critical care medicine. 2002 Jul 15; 166(2): 215-35. https ://doi.org/10.1 164 /rccm. 2109105

[13] Valimahamed-Mitha S, Berteloot L, Ducoin H, et al. Lung involvement in children with lysinuric protein intolerance. Journal of inherited metabolic disease. 2015 Mar; 38(2): 257-63. https : //doi.org/10.1007/s10545-014-9777-5

[14] Parto K, Svedström E, Majurin ML, et al. Pulmonary manifestations in lysinuric protein intolerance. Chest. 1993 Oct; 104(4): 1176-82. PMid: 8404187. https ://doi.org/10.1378/chest.104.4.11 76

[15] Mauhin W, Habarou F, Gobin S, et al. Update on Lysinuric Protein Intolerance, a Multi-faceted Disease Retrospective cohort analysis from birth to adulthood. Orphanet Journal of Rare Diseases. 2017 Jan 5; 12(1): 3. https://doi .org/10.1186/s13023-016-0550-8

[16] Medeiros LJ, Kaynor B, Harris NL. Lupus lymphadenitis: report of a case with immunohistologic studies on frozen sections. Human pathology. 1989 Mar; 20(3): 295-9. https ://doi.org/10.1016/ 0046-8177 (89) 90141-X

[17] Fox RA, Rosahn PD. The lymph nodes in disseminated lupus erythematosus. The American Journal of Pathology. 1943 Jan; 19(1): 73-99. PMid: 19970684. 
[18] Klemperer P, Pollack AD, Baehr G. Pathology of disseminated lupus erythematosus. Arch Pathol Lab Med. 1941; 32: 569-631.

[19] Masahiro K, Koichi O. Cervical lymphadenopathy, fever and leukopenia (Histiocytic-necrotizing lymphadenitis or Kikuchi disease). AJSP: Reviews \& Reports. 2004; 9: 199-205.

[20] Wear DJ, Margileth AM, Hadfield TL, et al. Cat scratch disease: a bacterial infection. Science. 1983 Sep 30; 221(4618): 1403-5. PMid: 6612349. https://doi.org/10.1126/science.6612349

[21] Janka G. Familial hemophagocytic lymphohistiocytosis. European journal of pediatrics. 1983; 140: 221-230. PMid: 6354720. https: //doi.org/10.1007/BF00443367
[22] Cooper N, Rao K, Gilmour K, et al. Stem cell transplantation with reduced-intensity conditioning for hemophagocytic lymphohistiocytosis. Blood. 2006 Feb 1; 107(3): 1233-6. https ://doi.org/10 .1182/blood-2005-05-1819

[23] Ouachée-Chardin M, Elie C, de Saint Basile G, et al. Hematopoietic stem cell transplantation in hemophagocytic lymphohistiocytosis: a single-center report of 48 patients. Pediatrics. 2006 Apr; 117(4): e743-50. https://doi.org/10.1542/peds.2005-1789

[24] Horne A, Janka , Maarten Egeler R, et al. Haematopoietic stem cell transplantation in haemophagocytic lymphohistiocytosis. British Journal of Haematology. 2005 Jun; 129(5): 622-30. https ://doi . org $/ 10.1111 / \mathrm{j} .1365-2141.2005 .05501 . \mathrm{x}$ 